\title{
ÁGUA DE ABASTECIMENTO EM INDÚSTRIAS FRIGORÍFICAS NO SUL DO BRASIL: UM ESTUDO SOBRE SUA QUALIDADE MICROBIOLÓGICA
}

\author{
Ana Paula Dutra Resem Brizio ${ }^{1}$ \\ ${ }^{1}$ Laboratório de Tecnologia de Alimentos (LTA) - Escola de Química e Alimentos (FURG) - E-mail: anabrizio@ yahoo.com.br
}

\section{RESUMO}

O presente trabalho teve por objetivo avaliar a qualidade microbiológica da água de abastecimento utilizada em indústrias frigoríficas de aves e suínos no Estado do Rio Grande do Sul, comparando os resultados com os parâmetros de potabilidade da legislação brasileira vigente. Os resultados demonstraram que todas as amostras analisadas estão dentro dos padrões estabelecidos pela legislação brasileira. Portanto, as águas de abastecimento provenientes das indústrias frigoríficas avaliadas atenderam os parâmetros de potabilidade, apresentando qualidade satisfatória.

Palavras-chave: Água, manancial subterrâneo, frigoríficos, parâmetros de potabilidade

\section{WATER SUPPLY IN SLAUGHTERHOUSES IN SOUTHERN BRAZIL: A STUDY ON ITS MICROBIOLOGICAL QUALITY}

\begin{abstract}
This study aimed to evaluate the microbiological quality of the water supply used in swine and poultry slaughterhouses in the state of Rio Grande do Sul, comparing the results with the potability parameters of Brazilian law. The results showed that all samples are in accordance with the standards established by the Brazilian legislation. Thus, we can conclude that the water supply from the slaughterhouses evaluated met the potability parameters, showing a satisfactory quality.
\end{abstract}

Keywords: Water, underground water, slaughterhouses, potability parameters 


\section{INTRODUÇÃO}

Nas indústrias de alimentos a água potável é de capital importância, devendo ser fornecida em quantidade suficiente e com qualidade adequada para o desenvolvimento de suas atividades (NUNES et al., 2013).

A água de abastecimento em indústrias de produtos de origem animal precisa sofrer criterioso controle para garantir a qualidade do produto final e atender a legislação vigente. Nesse sentido, a água deve ser um dos principais insumos controlados, a fim de manter a qualidade, eficácia, segurança e credibilidade dos alimentos fornecidos à população em geral (MIERZWA \& HESPANHOL, 2005).

As águas subterrâneas oriundas de poços artesianos constituem-se importantes fontes de suprimento de água em empresas de alimentos. Tradicionalmente, são consideradas seguras para o consumo "in natura". No entanto, podem contaminar-se por impurezas pela abertura do poço, por águas de chuvas que penetram em frestas e, principalmente, por contaminação direta do lençol freático por material orgânico, proveniente de águas residuais urbanas $\mathrm{e}$ rurais (GONZALEZ, 1982; VALIAS et al., 2002; MACÊDO, 2004).

Apesar da água não fornecer as condições ideais à multiplicação dos micro- organismos patogênicos, estes geralmente sobrevivem nela tempo suficiente para permitir sua transmissão hídrica (AMARAL, 1996; NUNES, et al. 2013). Porém, a identificação de patógenos na água é, quase sempre, morosa, complexa e onerosa. Por isso, tradicionalmente recorre-se a identificação dos micro-organismos indicadores de contaminação, na interpretação de que sua presença na água indicaria a introdução de matéria de origem fecal (humana ou animal) e, portanto, o risco potencial da presença de micro-organismos patogênicos (JAY, 2005). Dentre as bactérias presentes na água, o grupo dos coliformes é o melhor indicador de poluição fecal (LEE \& COLE, 1993; AMARAL, et al. 2003; BRASIL, 2011), sendo utilizado porque estão presentes nas fezes dos animais endotérmicos (VALIAS et al., 2002; JAY, 2005).

Diante do exposto, o presente trabalho teve por objetivo avaliar a qualidade microbiológica da água de abastecimento (através de análises de quantificação de micro-organismos indicadores) proveniente da rede privada de mananciais subterrâneos, utilizada em indústrias frigoríficas no Estado do Rio Grande do Sul. 


\section{MATERIAL E MÉTODOS}

Esta pesquisa foi desenvolvida em indústrias frigoríficas de aves e suínos, com Serviço de Inspeção Federal (SIF), situadas no estado do Rio Grande do Sul, durante o período de janeiro de 2011 a dezembro de 2012, totalizando a coleta de cento e vinte (120) amostras de água da rede privada de abastecimento (manancial subterrâneo).

As amostras de água foram colhidas mensalmente em cada estabelecimento após captação e tratamento com hipoclorito de sódio ( $\mathrm{NaClO}$ ) (dosagem máxima de 2ppm de $\mathrm{NaClO})$ em pontos de saída de água dentro dos frigoríficos. As amostras foram colhidas em frascos de vidro esterilizados e, imediatamente após, acondicionadas em caixas contendo gelo e enviadas aos laboratórios para realização das análises em tempo inferior a 24 horas.

Foram realizadas análises de contagens de coliformes totais e Escherichia coli conforme metodologia recomendada pela American Public Health Association - APHA (2001). E, em complementação aos indicadores microbiológicos, foram realizadas também análises físico-químicas de cor, $\mathrm{pH}$, turbidez e cloro residual livre, segundo metodologia APHA (2005).

Os resultados foram comparados com os padrões de potabilidade estabelecidos pela
Portaria n ${ }^{\circ}$ 2.914/2011 da Agência Nacional de Vigilância Sanitária - ANVISA (BRASIL, 2011).

\section{RESULTADOS E DISCUSSÃO}

Os resultados obtidos nas análises microbiológicas e físico-químicas realizadas nas amostras de água foram registrados (Tabela 1).

De acordo com Putnam \& Graham (1993) e Macêdo (2004) o cloro e o hipoclorito de sódio são os agentes mais simples e eficazes para a desinfecção de um poço, bomba, reservatório ou sistema de distribuição, sendo econômicos, convenientes e efetivos. A sua ação é atribuída principalmente à oxidação e ao efeito letal sobre organismos vegetais e animais. Por isso, a legislação brasileira estabelece que após a desinfecção, a água deve manter um teor mínimo de cloro residual livre de $0,2 \mathrm{mg} / \mathrm{l}$ em qualquer ponto da rede de distribuição (BRASIL, 2011), valor mínimo mantido por todas as amostras de água avaliadas neste estudo.

Os baixos índices de turbidez detectados mostram a existência de pequenas quantidades de matéria orgânica/inorgânica e organismos microscópicos suspensos nas amostras. 
Tabela 1. Resultados fisico-químico das amostras de água coletadas em frigoríficos no Estado do Rio Grande do Sul.

\begin{tabular}{|c|c|c|}
\hline Análises & Resultados & Padrão Legal* $^{*}$ \\
\hline \multicolumn{3}{|c|}{ Microbiológicas } \\
\hline Coliformes Totais & $<1,0 \mathrm{X} 10^{0} \mathrm{UFC} / 100 \mathrm{ml}$ & $<1,0 \mathrm{X} 10^{0} \mathrm{UFC}^{* *} / 100 \mathrm{ml}$ \\
\hline Escherichia coli & $<1,0 \mathrm{X} 10^{0} \mathrm{UFC} / 100 \mathrm{ml}$ & $<1,0 \mathrm{X} 10^{0} \mathrm{UFC} / 100 \mathrm{ml}$ \\
\hline \multicolumn{3}{|c|}{ Físico-químicas } \\
\hline Cor & $2,83 \pm 0,97 \mathrm{Uh}$ & Máx. 15,0 uH ${ }^{* * *}$ \\
\hline $\mathrm{pH}$ & $6,82 \pm 0,22$ & $6,0-9,5$ \\
\hline Cloro residual livre & $0,41 \pm 0,15 \mathrm{mg} / \mathrm{l}_{\mathrm{Cl} 2}$ & Mín.0,2mg/l $\mathrm{l}_{\mathrm{Cl}}$ \\
\hline Turbidez & $0,24 \pm 0,38 \mathrm{uT}$ & Máx. 5,0 uT $\mathrm{T}^{* * * *}$ \\
\hline
\end{tabular}

${ }^{*}$ Conforme Portaria ${ }^{\circ}$ 2.914/2011 (Brasil, 2011).

${ }^{* *}$ Unidade Formadora de Colônia.

${ }^{* * *}$ Unidade Hazen (mgPt-Co/L).

**** Unidade de Turbidez.

Enquanto os resultados de cor indicaram águas contendo poucas substâncias coloidais orgânicas e minerais dissolvidas nas amostras. Estes parâmetros são importantes, pois segundo a Organização Mundial da Saúde (OMS, 1995), partículas e substâncias coloidais podem proteger os microorganismos da ação do agente desinfetante durante o tratamento da água.

Os valores de $\mathrm{pH}$ das amostras apresentaram resultados dentro do limite legal brasileiro, o qual preconiza a diminuição de problemas de incrustação e corrosão das redes de distribuição, já que, em águas de abastecimento, baixos valores de $\mathrm{pH}$ podem contribuir para sua corrosividade e agressividade, enquanto valores elevados aumentam a possibilidade de incrustações (BRASIL, 2011).

Os resultados microbiológicos revelaram que todas as amostras de água atenderam aos padrões estabelecidos pela legislação brasileira (BRASIL, 2011), apresentando ausência de unidades formadoras de colônia em 100ml de água na quantificação dos micro-organismos do grupo dos coliformes totais e Escherichia coli. Resultados diferentes foram encontrados por Ramos et al. (2007), os quais analisaram 60 amostras de águas utilizadas em indústrias de alimentos localizados no Estado do Rio de Janeiro, encontrando $6,7 \%$ de não conformidades nas análises microbiológicas, e, por Scandolera et al. (2001), que avaliaram amostras de água do Campus da UNESP de 
Jaboticabal onde cerca de $35 \%$ das amostras apresentaram-se impróprias para o consumo humano, devido ao não atendimento aos parâmetros bacteriológicos legais.

A ausência de detecção das bactérias analisadas neste estudo indica boa qualidade higiênico-sanitária das águas de abastecimento utilizadas nos frigoríficos avaliados. A conformidade com os parâmetros microbiológicos é importante, pois a água entra em contado direto com os produtos elaborados, podendo se tornar um veículo de contaminação biológica (RAMOS et al., 2007).

A qualidade verificada nas amostras esta fortemente atribuída aos tipos de captação e aos solos nas bacias de captação. Segundo Valias et al. (2002) a água proveniente de poços tradicionalmente apresenta baixos níveis de contaminação, sendo considerada muito pura, pois são oriundas de água das chuvas que sofrem filtração natural pelo solo até chegar a uma camada impermeável constituída de argila ou rocha onde forma-se o lençol freático.

De acordo com Brasil (2011) e Nunes et al. (2013) a falta de isolamento de coliformes totais nas amostras, embora não guarde relação exclusiva com contaminação de origem fecal, indica integridade do sistema de distribuição, enquanto a ausência de
Escherichia coli evidencia uma boa eficiência do tratamento realizado nas águas avaliadas, neste caso, adição de hipoclorito de sódio.

Cabe salientar, também, os cuidados complementares tomados pelas empresas, como: limpeza das caixas d'água e cisternas a cada seis meses e, manutenção de caixas d'água sempre tampadas, como medidas tomadas pelas empresas avaliadas para prevenir a contaminação da água já tratada, mantendo desta forma sua qualidade desde a captação até a produção do alimento. De acordo com Galletti et al. (2010), a implantação destes cuidados no sistema de distribuição e a monitorização microbiológica da água de abastecimento na indústria de produtos de origem animal constitui uma forma de aplicação das Boas Práticas de Fabricação (BPF), importante ferramenta na elaboração de produtos alimentícios seguros ao consumo humano.

\section{CONCLUSÃO}

Os resultados demonstraram que as amostras analisadas encontram-se dentro dos padrões estabelecidos pela legislação brasileira. Desta forma, as águas de abastecimento provenientes das indústrias frigoríficas avaliadas atenderam os parâmetros de potabilidade, apresentando qualidade microbiológica satisfatória. 


\section{AGRADECIMENTOS}

A autora agradece ao Ministério da Agricultura Pecuária e Abastecimento (MAPA) pelo apoio prestado e as empresas frigoríficas que permitiram a realização da pesquisa em suas plantas fabris.

\section{REFERÊNCIAS BIBLIOGRÁFICAS}

AMARAL, L. A. 1996. Controle de qualidade microbiológica da água utilizada em avicultura. In: MACARI, M. Água na Avicultura. $1^{\circ} \mathrm{ed}$. Jaboticabal: FUNEP, cap. 7 , pp. $93-117$.

AMARAL, L. A.; NADER FILHO, A.; ROSSI JUNIOR, O. D.; FERREIRA, F. L. A.; BARROS, L. S. S. 2003. Água de consumo humano como fator de risco à saúde em propriedades rurais. Revista de Saúde Pública, São Paulo, v. 37, n. 4, pp. 510-514. APHA - American Public Health Association. Compendium of Methods for the Microbiological Examination of Foods. Washington. DC, pp. 676, 2001.

APHA - American Public Health Association. Microbiological Examination. In: Standard Methods for the Examination of Water and Wastewater. Washington. DC, pp. 281, 2005.
BRASIL. 2011. Ministério da Saúde. Portaria $\mathrm{n}^{\circ} 2.914$, de 12 de dezembro de 2011. Dispõe sobre os procedimentos de controle e vigilância da qualidade da água para consumo humano e seu padrão de potabilidade.

GAlletTI, J. P.; FLORESTA, A. C. F.; SANTOS, H. D.; MINHARRO, S. 2010. Qualidade de água de abastecimento na indústria de produtos de origem animal: revisão bibliográfica. Enciclopédia biosfera, Goiânia, v.6, n.10, pp. 1-10.

GONZALEZ, R.G. 1982. Estudio bacteriológico del agua de consumo en una comunidad mexicana. Boletim de la Oficina Sanitaria Panamericana, Washington, v.93, n.2, pp. $127-141$.

JAY, J. M. 2005. Microbiologia de alimentos. 6. ed. Porto Alegre: Artmed. pp. 243-251

LEE, R.J.; COLE, S.R. 1993. Internal quality control for water bacteriology. Journal of Applied Bacteriology, Amsterdam, v. 76, n. 3 , pp. $270-274$.

MACÊDO, J. A. B. 2004. Águas \& Águas. 2. ed. Juiz de Fora: Ortofarma. 977 p. MIERZWA, J. C.; HESPANHOL, I. 2005. Água na indústria: uso racional e reuso, São Paulo: Ed. Oficina de Textos. 122 p.

NUNES, M. M.; MOTA, A. L. A. A.; CALDAS, E. D. 2013. Investigation of food and water microbiological conditions and 
foodborne disease outbreaks in the Federal

District, Brazil. Food Control, Amsterdam, v. 34, pp. 235-240.

OMS - ORGANIZACIÓN MUNDIAL DE LA SALUD. 1995. Guia para la calidad del água potable. v. 1, Recomendaciones. $2 \mathrm{ed}$. Ginebra: OMS. 195 p.

PUNTAM, S. W.; GRAHAM, J. D. 1993.

Chemicals versus microbials in drinking water: a decision sciences perspective. Journal of American Water Works Association, Denver, v. 85, n.3, pp. 57-61.

RAMOS, G. D. M.; GASPAR, A.; GUERRA, C. A.; CHAGAS, V. R. S. 2007. Qualidade da água utilizada em indústrias de alimentos localizadas no estado do Rio de Janeiro. Revista Universidade Rural, Série Ciências da Vida, Rio de Janeiro, v. 27 n. 1, pp. 33-39. SCANDOLERA, A. J.; PALHARES, J. C.; DE LUCAS JUNIOR, J.; AMARAL, L. A.; MENDONÇA, R. P.; OLIVEIRA, G. P. 2001. Avaliação de parâmetros químicos, microbiológicos e parasitológicos de águas de abastecimento da UNESP e residuária, no município de Jaboticabal, Estado de São Paulo. Semina: Ciências Agrárias, Londrina, v. 22, n.1, pp. 83-91.

VALIAS, A. P. G. S.; ROQUETO, M. A.; HORNINK, D. G.; KOROIVA, E. H.; VIEIRA, F. C.; ROSA, G. M.; SILVA, M. A. M. L. 2002. Avaliação da qualidade microbiológica de águas de poços rasos e de nascentes de propriedades rurais do município de São João da Boa Vista - São Paulo. Arquivos de Ciências Veterinárias e Zoologia, Umuarama, v. 5, n.1, pp. 21-28.

Recebido em:25/6/2013 Aceito para publicação em: 11/08/2014 